\title{
Effect of carbon nanofibers content on thermal properties of ceramic
}

\author{
nanocomposites
}

\author{
A. Borrell ${ }^{1 *}$, V.G. Rocha ${ }^{2}$, R. Torrecillas ${ }^{1}$, A. Fernández ${ }^{2}$ \\ ${ }^{1}$ Centro de Investigación en Nanomateriales y Nanotecnología (CINN) (Consejo Superior de \\ Investigaciones Científicas - Universidad de Oviedo - Principado de Asturias), Parque Tecnológico \\ de Asturias, Llanera 33428 (Asturias), Spain \\ ${ }^{2}$ ITMA Materials Technology, Parque Tecnológico de Asturias, Llanera 33428 (Asturias), Spain \\ *Corresponding author: Tel.: +34 985980 058; Fax: +34 985265574 . \\ E-mail address: a.borrell@cinn.es (A. Borrell)
}

\begin{abstract}
The thermal properties of CNFs-alumina and CNFs-zirconia nanocomposites densified by spark plasma sintering technique were evaluated. The influence of CNFs content and type of ceramic matrix on thermal conductivity of ceramic-CNFs materials, measured by the laser-flash method, was studied. The effect of CNFs depends noticeably on the ceramic component and thus, an increase of $83 \%$ and a decrease of $97 \%$ in thermal conductivity at room temperature is observed when 80 vol.\% of CNFs is added to $\mathrm{ZrO}_{2}$ and $\mathrm{Al}_{2} \mathrm{O}_{3}$, respectively. However, even if the thermal conductivity is lower, the efficiency of heat transfer to the environment in $\mathrm{CNFs} / \mathrm{Al}_{2} \mathrm{O}_{3}$ nanocomposites is better than that corresponding to monolithic alumina. This behavior is due to CNFs arrangement in dense
\end{abstract}


materials. Considering the low electrical resistivity for CNFs/ $\mathrm{Al}_{2} \mathrm{O}_{3}$ and $\mathrm{CNFs} / \mathrm{ZrO}_{2}$ materials $\left(10^{-1}-10^{-2} \Omega \cdot \mathrm{cm}\right)$, these nanocomposites are promising candidates as thermoelectric materials that require low thermal conductivity, but high electrical conductivity.

Keywords: Spark plasma sintering, thermal properties, carbon nanofibers, ceramic nanocomposites

\section{INTRODUCTION}

Carbon nanotubes (CNTs) and carbon nanofibers (CNFs) have attracted ever increasing attention since their discovery [1-3]. These carbon nanofilaments are promising candidates for many applications based on their extraordinary physical and electrical properties due to their tubular structure, e.g., low weight, high Young's modulus and tensile strength and high electrical conductivity. The increasing interest in using CNFs instead of CNTs is related with the higher production rate and lower price that makes them very interesting for massive application even if their properties are not as good as those corresponding to CNTs. One of the most promising uses of CNFs is in the development of nanocomposites with new functional properties, where the CNFs are used as novel fillers and binders to improve their mechanical and electrical properties [4,5]. Ceramics can sustain high temperature and have a high degree of hardness, but the most noted shortcoming is its inherent brittleness, which has limited its extensive applications [6]. Because of this fact, as happened with CNTs, CNFs-reinforced ceramic nanocomposites have become an exciting 
field of intense research, mainly focused on improving the electrical and mechanical properties through incorporating carbon nanofibers [7-10].

According to theoretical predictions [11], thermal conductivity of individual CNTs could reach values as high as $6600 \mathrm{~W} / \mathrm{mK}$ along the tube direction at room temperature. Kim et al. measured the thermal conductivity of an individual CNT being around $3000 \mathrm{~W} / \mathrm{mK}$ [12]. Both theoretically predicted and experimentally measured thermal conductivities for an individual CNT were reported to be very high. Nevertheless, most experimental measurements using assemblies of nanotubes, e.g., bundles, ropes or films, revealed that the thermal conductivity ranges only from 20 to $200 \mathrm{~W} / \mathrm{mK}$ [13-16]. Therefore, the effective thermal conductivity of CNTs is not very clear. As far as we know, there have not been any reported investigations on thermal properties of CNFs-reinforced ceramic nanocomposites and only very few works in CNTs-reinforced ceramic nanocomposites have explored these kinds of properties $[11,12]$. If the combination of low thermal conductivity and high electrical conductivity is confirmed, a promising use for these nanocomposites could be as thermoelectric materials. These materials have many applications in the conversion of thermal energy to electrical power and in solid-state cooling $[17,18]$. In general, material development schemes to improve thermoelectric conversion efficiency are driven by the need to maximize the Seebeck coefficient, and to balance the competing requirements of low electrical resistivity and low thermal conductivity. Polycrystalline materials, rather than single crystals, are generally used in macroscopic thermoelectric devices because they tend to be less costly to produce, are more easily fabricated into appropriate geometries for the thermoelectric elements, and have better fracture resistance. Much interest is emerging concerning so-called nanocomposite materials, which combine multiple phases of 
nanometer-scale dimensions. Among nanostructures, carbon nanotubes and carbon nanofibers have generated special interest due to their unusual properties, including both their thermal and electrical behavior.

In the present study, we discuss the thermal properties of CNFs/Alumina and CNFs/Zirconia nanocomposites obtained by the spark plasma sintering (SPS) technique. The thermal conductivity and heat transfer of the resultant materials were evaluated and compared. The effect of CNF addition on thermal behavior of ceramic nanocomposites is discussed.

\section{EXPERIMENTAL PROCEDURE}

The materials used in this study were commercial carbon nanofibers (CNFs) having average outer diameter of 20-80 nm and lengths $>30$ microns, supplied by Group Antolín Engineering, (Burgos, Spain). These CNFs were generated via vapor phase growth (VGCNFs) using a floating catalyst of nickel in solution (6-8\%) [19]. $\alpha-\mathrm{Al}_{2} \mathrm{O}_{3}$ nanopowder (Taimei TM-DAR Chemicals Co. Ltd, Japan) with average particle size of $153 \mathrm{~nm}$ and a purity of $99.99 \%$ and $\mathrm{ZrO}_{2}$ (TZ-3YB) nanopowders (Tosoh Corp., Japan), with average particle size of $180 \mathrm{~nm}$ were used as ceramic raw materials. The powder mixtures, $\mathrm{CNFs} / \mathrm{Al}_{2} \mathrm{O}_{3}=0 / 100,20 / 80,80 / 20$ and $100 / 0$ vol. $\%$ and $\mathrm{CNFs} / \mathrm{ZrO}_{2}=0 / 100,20 / 80,80 / 20$ and 100/0 vol.\%, were prepared in ethanol (Panreac Quimica) with a high energy attrition milling (Union Process, EE.UU) working at $400 \mathrm{rpm}$ and milling times of 1 hour, using alumina media of $2 \mathrm{~mm}$ diameter. After milling, the resultant slurry was firstly dried under stirring at $60{ }^{\circ} \mathrm{C}$ and then at $110{ }^{\circ} \mathrm{C}$ in oven in order to remove solvent traces. The dried powders were sieved under 63 microns being ready to be sintered by SPS. 
The powder samples were placed into a graphite die with an inner diameter of $20 \mathrm{~mm}$ and cold uniaxially pressed at $30 \mathrm{MPa}$. Then, they were introduced in a spark plasma sintering apparatus HP D 25/1 (FCT Systeme GmbH, Germany) under low vacuum (10 ${ }^{-1} \mathrm{mbar}$ ) and sintered at $1500{ }^{\circ} \mathrm{C}$ for 1 min under an applied pressure of $80 \mathrm{MPa}$ and a heating rate of 100 ${ }^{\circ} \mathrm{C} \min ^{-1}$. Bulk density of the sintered bodies was measured by the geometric method from weight and geometric volume of the material. Relative densities were calculated as relation between geometrical and theoretical densities. The TEM photographs were obtained with a transmission electron microscope (JEOL, $2000 \mathrm{FX}$ ) and the bulk CNFs sample was previously cut on a Reicher Ultracut E ultramicrotome. Thermal diffusivity $(\alpha)$ of each plate specimen was measured at various temperatures in the $25-1000{ }^{\circ} \mathrm{C}$ range during heating using the laser-flash technique (Thermaflash 2200, Holometrix, Bedford, MA) in Ar atmosphere. The precision of the thermal diffusivity measurements was $\pm 5 \%$. Parallelepiped shaped specimens of $(8.8 \times 8.8) \mathrm{mm}$ and about $2 \mathrm{~mm}$ of thickness were used for these measurements. Before thermal diffusivity measurements, both the front and the back faces of each specimen were coated with a thin gold layer, followed by deposition of a thin carbon layer, in order to enhance heat absorption at the surface and to avoid direct transmission of the laser beam. Effective thermal diffusivity $(\alpha)$ was calculated using Degiovanni's method implemented in the equipment software [20]. The specific heat $(C p)$ as a function of temperature was calculated from the chemical composition and the heat capacity data of the constituent oxides $\left(\mathrm{Al}_{2} \mathrm{O}_{3}\right.$ and $\left.\mathrm{ZrO}_{2}\right)$ and CNFs, 0.79, 0.28 and 1.19 $\mathrm{J} / \mathrm{gK}$, respectively, reported in the literature [21,22]. Thermal conductivity $(k)$ was then obtained from $\alpha, C p$ and the density $(\rho)$ using the following relation: $k=\alpha \rho C p$. The electrical resistivity of composite materials was determined according to ASTM C611. The 
specimens were placed between two sheets of copper connected to a power supply, which allowed working at different current intensities. The measures were carried out by fixing the intensity of the current at $0.5 \mathrm{~A}$ using a multimeter of fixed pegs (9.55 mm separation), determining the voltage drop.

\section{RESULTS AND DISCUSSION}

Table 1 summarizes the density values and relative density of the different $\mathrm{CNFs} / \mathrm{Al}_{2} \mathrm{O}_{3}$ and $\mathrm{CNFs} / \mathrm{ZrO}_{2}$ composites and monolithic materials sintered by SPS at $1500{ }^{\circ} \mathrm{C}$. The sintering conditions for CNFs based materials were studied in a previous work. Concerning the temperature, it was found that $1500{ }^{\circ} \mathrm{C}$ is the suitable temperature for obtaining high density carbon materials [23]. Therefore, this maximum temperature has been fixed for all the materials prepared in this work in order to minimize the influence of sintering parameters on this study. Theoretical densities were calculated by the rule of mixtures, taking 3.97, 6.08 and $2.00 \mathrm{~g} / \mathrm{cm}^{3}$ as the theoretical densities for alumina, zirconia and carbon nanofibers, respectively. Pure ceramic materials are fully densified at these sintering conditions as was expected. Bulk carbon nanofiber material has a relative density of $\sim 90 \%$ that is significantly high for this type of material [24]. It is important to remark that high density carbon materials are conventionally prepared by successive cycles of impregnationcarbonization-graphitization steps with the remaining porosity being usually higher than $15 \%$. By direct pressing and heating during the SPS process, a material with higher density was obtained and it was processed in a very short period of time. The addition of ceramic phases improves the densification of carbon materials as can be observed by comparing the relative density of the composites with high CNF content (80 vol.\%) with the 
corresponding pure CNF material. Regarding ceramic matrix materials (CNFs content 20 vol.\%), the density is close the theoretical density of $\sim 99 \%$.

The evolution of thermal conductivities with temperature for sintered monolithic and nanocomposites material $\left(\mathrm{CNFs} / \mathrm{Al}_{2} \mathrm{O}_{3}\right.$ and $\left.\mathrm{CNFs} / \mathrm{ZrO}_{2}\right)$ with different $\mathrm{CNF}$ content are shown in Figure 1. The thermal conductivity values of the CNF bulk samples decreased with increasing temperature. This is the typical behavior for crystalline materials in which a dependence of thermal conductivity with $1 / \mathrm{T}$ at high temperatures is expected due to phonon disharmony. The values of thermal conductivities for all materials studied are closer at temperatures above $800{ }^{\circ} \mathrm{C}$. At room-temperature, the thermal conductivity for the CNF bulk sample has a value of only $7.6 \mathrm{~W} / \mathrm{mK}$. This value is much lower than the experimentally measured thermal conductivity of ordered CNT-based materials such as ropes or films $[15,16]$ and it is even three orders of magnitude lower than the theoretical predictions for individual CNTs $(\sim 6000 \mathrm{~W} / \mathrm{mK})$ [11]. This extremely low thermal conductivity of carbon nanofilament bulk materials has been previously reported for CNTbased materials and it is due to a combination of multiple physical effects [24].

The thermal conductivity is dominated by phonons. At high temperatures, which include room temperature, the phonon-phonon Umklapp scattering makes the major contribution to thermal conductivity. The thermal-conduction mechanism for the assemblies of nanofibers involves phonon thermal transport along the fiber, coupled with thermal diffusion between adjacent fibers. Heat loss from the interfibers thermal diffusion also degraded the longitudinal thermal conductivity of the nanofibers. Therefore, although the thermal 
conductivity of an individual carbon nanofilament could be as high as the theoretical models predict, from a macroscopic point of view it is critical to know how these nanofilaments are distributed in a bulk material.

The TEM micrographs in Figure 2 show the morphology of carbon nanofiber raw material (Fig. 2a) and a detailed microstructure of SPS sample (Fig. 2b). In Figure 2a it can be seen how carbon nanofibers are forming aggregates as a consequence of the production method. The CNF compact became fairly dense after SPS in spite of low consolidation temperature used in the process. This indicates that SPS is an excellent technique to prepare CNF bulk samples. It can also be seen how the nanofibers were still tangled randomly after the SPS processing. On the other hand, nanosized pores could be clearly observed between the fibers that are responsible for the $10 \%$ total porosity of the material.

It is important to note how many nanofibers were unavoidably curved or kinked due to the pressure applied during SPS processing (Fig. 2b). The heat flow travelling along the fiber is blocked at the sites of the curves or kinks and therefore the thermal conductivity of the CNF bulk materials is lowered. The curves and kinks should be removed if we want to increase the thermal conductivity. However, it would be difficult to straighten the nanofibers while densifying them into bulk forms in practice.

In the case of $\mathrm{CNFs} / \mathrm{Al}_{2} \mathrm{O}_{3}$ nanocomposites, the thermal conductivity at room temperature decreases with increasing CNFs content (Fig. 1). Nevertheless, the thermal conductivity values of the $\mathrm{CNFs} / \mathrm{ZrO}_{2}$ nanocomposites increases with the addition of CNFs. Considering the thermal conductivities of alumina $(30-35 \mathrm{~W} / \mathrm{mK})$, zirconia $(2-3 \mathrm{~W} / \mathrm{mK})$ and CNFs $(7-8$ 
$\mathrm{W} / \mathrm{mK}$ ) monolithic materials, it can be concluded that both types of nanocomposites follow the rule of mixtures.

Moreover, it is known how the presence of porosity decreases the thermal conductivity of solid materials. From the analysis of the results corresponding to the CNFs-alumina nanocomposites, it seems that the porosity could be the only property affecting the thermal conductivity, being lower when the porous content is higher. Nevertheless, in the case of CNFs-zirconia nanocomposites, the relation between thermal conductivity and porosity is the opposite. Therefore, more factors are governing the thermal behavior of these materials. The changes of thermal properties of $\mathrm{CNFs} / \mathrm{Al}_{2} \mathrm{O}_{3}$ and $\mathrm{CNFs} / \mathrm{ZrO}_{2}$ nanocomposites with respect to the CNF content can be explained as follows: the interaction of phonons with point defects will be the dominating scattering process and the maximum value of thermal conductivity will depend on the competition between various scattering processes (boundary, point defect, phonon, etc.). For different samples of the same material, the maximum will depend on the density of point defects [25]. Some efforts have been made to investigate the thermal properties of ceramic-based CNTs nanocomposite. Zhan et al. [26] synthesized the SWCNTs-Alumina nanocomposite which depicted an increase in electrical conductivity but a decrease in thermal conductivity with an increase in the CNTs content. They also found anisotropy in thermal conductivity of the composites that may be directly related to the degree of alignment of ropes in the composites and the anisotropic characteristics of the thermal conductivity of ropes of carbon nanofilaments themselves [15]. The decrease in thermal conductivity by introduction of SWCNTs, even if SWCNTs was a promising component for improving this property, may be attributed to the difference of thermal properties of an individual tube and ropes [14]. Microstructural observations 
indicate that ropes of SWCNTs are intertwined with alumina matrix [27], suggesting that a significant degree of curvature or bending occur in the ropes. This feature was also observed in carbon nanofiber SPS material prepared in this work and it can be expected for all the nanocomposites studied. Then, CNFs arrangement is a critical aspect of bulk materials for their thermal behavior and, in the case of CNFs nanocomposites the thermal conductivity is limited by the content of the component with lower $k$.

From the macroscopic point of view, it is common knowledge in heat transfer that when lateral surface area increases, the heat transfer rate to the environment also increases. In this study, we have investigated if this effect was directly related to thermal conductivity. Then, a comparative study was carried out between $\mathrm{CNFs} / \mathrm{Al}_{2} \mathrm{O}_{3}$ and $\mathrm{CNFs} / \mathrm{ZrO}_{2}$ nanocomposite samples with different CNFs contents prepared in this work. In order to carry out this study, the temperature data extracted from the SPS tests were analyzed. In the SPS equipment the temperature is measured by an optical pyrometer in the upper part of the apparatus. In a typical SPS cycle, the following operational steps can be identified: vacuum, pressing, heating, stay and cooling. Although the cooling rate can be also controlled, in these tests the samples were free-cooled while the temperature is recorded. In Figure 3 the cooling curve is represented for the different samples prepared by SPS, that is, the temperature measured by the optical pyrometer in function of time during the free-cooling step. It can be seen, how the highest value the cooling rate correspond to the CNFs material and the nanocomposites with highest CNF content. This means that the rate of heat transfer to the environment is clearly enhanced by CNF addition. In this case, as the heat flows from the material surface to the environment, it is not necessary to flow through the material, the 
carbon nanofibers arrangement and heat loss from the interfibers thermal diffusion are less important and the proportion of carbon nanofibers present in the surface determines the material behavior. From this study it can be concluded that the heat transfer phenomenon in these nanocomposites seems to be independent of the thermal conductivity and the influence of CNFs content in both processes is opposite.

The electrical resistivity of CNF bulk material was measured at room temperature is $\sim 10^{-2}$ $\Omega \mathrm{cm}$. This value is also achieved for ceramic-CNFs nanocomposites with high CNFs content (80 vol.\%). Moreover, CNFs-ceramic nanocomposites with only 20 vol.\% of CNFs show an electrical resistivity $\sim 10^{-1} \Omega \mathrm{cm}$, close to the electrical conductivity of bulk CNFs material and very much lower than monolithic alumina and zirconia ceramics. As can be observed, the electrical resistivity decreases drastically when the conductive phase has percolated. Then, the low electrical resistivity of the materials with high CNF content and their low thermal conductivity previously discussed make these materials very promising candidates for thermoelectric applications. For this application, high electrical conductivity combined with poor thermal conductivity is required, characteristics that are difficult to be found in the same material because both conductivities are usually linked.

\section{CONCLUSIONS}

Noticeably low thermal conductivity of CNF bulk material has been found. Although the excellent thermal conductivity of isolated CNT or CNF is recognized, carbon nanofilament arrangement and interfibers contact inside bulk material leads to a marked decrease in this property. It has been shown that thermal conductivity of CNFs-ceramic nanocomposites 
follows the rule of mixture while electrical conductivity is governed by the percolation theory. Hence, low electrical resistivity and low thermal conductivity nanocomposite materials which are required for thermoelectric application could be designed. In contrast with thermal conductivity, an improvement in heat transfer to the environment is found when carbon nanofibers are incorporated as reinforcement for both ceramic matrices.

\section{ACKNOWLEDGMENTS}

This work has been carried out with financial support of National Plan Projects MAT200601783 and MAT2007-30989-E to the Spanish Ministry of Science and Innovation and the Regional Project FICYT PC07-021 to the Asturias's Government. A. Borrell, acknowledges the Spanish Ministry of Science and Innovation for Ph.D. grant.

\section{REFERENCE}

1. S. Iijima, 1991, “Helical microtubules of graphitic carbon”, Nature, 354, 56-58.

2. D. S. Bethune, C. H. Kiang, M. S. De Vries, G. Gorman, R. Savoy, J. Vazquez and R. Beyers, 1993, "Cobalt-catalysed growth of carbon nanotubes with single-atomic-layer walls", Nature, 363, 605-607.

3. G. G. Tibbetts, D. W. Gorkiewicz and R. L. Alig, 1993, "A new reactor for growing carbon fibers from liquid-and vapor-phase hydrocarbons”, Carbon, 31, 809-814.

4. S. Maensiri, P. Laokul, J. Klinkaewnarong and V. Amornkitbamrung, 2007, "Carbon nanofiber-reinforced alumina nanocomposites: Fabrication and mechanical properties", Mater. Sci. Eng. A, 447, 44-50. 
5. A. Duszová, J. Dusza, K. Tomásěk, J. Morgiel, G. Blugand and J. Kuebler, 2008, “Zirconia/carbon nanofibers composite”, Scrip. Mater., 58, 520-523.

6. K. M. Prewo, 1989, "Fiber-reinforced ceramics: new opportunities for composite materials", Am. Ceram. Soc. Bull., 68, 395-400.

7. K. Hirota, Y. Takaura, M. Kato and Y. J. Miyamoto, 2007, "Fabrication of carbon nanofibre $(\mathrm{CNF})$-dispersed $\mathrm{Al}_{2} \mathrm{O}_{3}$ composites by pulsed electric-current pressure sintering and their mechanical and electrical properties", J. Mater. Sci., 42, 4792-4800.

8. K. Shimoda, T. Hinoki and A. Kohyama, 2010, "Effect of carbon nanofibers (CNFs) content on thermal and mechanical properties of CNFs/SiC nanocomposites", Comp. Sci. Technol., 70, 387-392.

9. A. Borrell, V.G. Rocha, R. Torrecillas and A. Fernández, 2011, "Surface coating on carbon nanofibers with alumina precursor by different synthesis routes", Comp. Sci. Technol., 71, 18-22.

10. A. Borrell, V. G. Rocha, R. Torrecillas and A. Fernández, 2011, "Improvement of $\mathrm{CNFs} / \mathrm{ZrO}_{2}$ composites properties with a zirconia nanocoating on carbon nanofibers by solgel method", J. Am. Ceram. Soc., DOI: 10.1111/j.1551-2916.2010.04354.x.

9. L. Kumari, T. Zhang, G. H. Du, W. Z. Li, Q. W. Wang, A. Datye and K. H. Wu, 2008, “Thermal properties of CNT-Alumina nanocomposites”, Comp. Sci. Technol., 68, 21782183.

10. G. D. Zhan, J. D. Kuntz, H. Wang, C. M. Wang, A. K. Mukherje, 2004, “Anisotropic thermal properties of single-wall-carbon nanotube-reinforced nanoceramics", Phil. Magaz. Lett., 84, 419-423. 
11. S. Berber, Y. K. Kwon and D. Tomanek, 2000, "Unusually high thermal conductivity of carbon nanotubes”, Phys. Rev. Lett., 84, 4613-4616.

12. P. Kim, L. Shi, A. Majumdar and P. L. McEuen, 2001, “Thermal transport measurements of individual multiwalled nanotubes”, Phys. Rev. Lett., 87, 215502-05.

13. W. Yi, L. Lu, D. L. Zhang, Z. W. Pan and S. S. Xie, 1999, "Linear specific heat of carbon nanotubes", Phys. Rev. B, 59, R9015-R9018.

14. J. Hone, M. Whitney, C. Piskoti and A. Zettl, 1999, “Thermal conductivity of singlewalled carbon nanotubes", Phys. Rev. B, 59, R2514-R2516.

15. J. Hone, M. C. Llaguno, N. M. Nemes, A. T. Johnson, J. E. Fischer, D. A. Walters, M. J. Casavant, J. Schmidt and R. E. Smalley, 2000, "Electrical and thermal transport properties of magnetically aligned single wall carbon nanotube films”, Appl. Phys. Lett., 77, 666-668.

16. D. J. Yang, Q. Zhang, G. Chen, S. F. Yoon, J. Ahn, S. G. Wang, Q. Zhou, Q. Wang, and J. Q. Li, 2002, “Thermal conductivity of multiwalled carbon nanotubes”, Phys. Rev. B, $66,165440-6$.

17. D. M. Rowe, 2006, Thermoelectrics handbook: macro to nano: CRC Press, Taylor and Francis.

18. L. E. Bell, 2008, “Cooling, heating, generating power, and recovering waste heat with thermoelectric systems", Science 321, 1457-1461.

19. L. Ci, J. Wei, B. Wei, J. Liang, C. Xu and D. Wu, 2001, "Carbon nanofibers and singlewalled carbon nanotubes prepared by the floating catalyst method", Carbon, 39, 329-335.

20. A. Degiovanni and M. Laurent, 1986, “A nouvelle technique d'identification de la diffusivité thermique pour la méthode «flash»”, Revue Physique Appliquée, 21, 229-237. 
21. M. W. Chase, (1998), NIST-JANAF Thermochemical Tables, 4th ed., J. Phys. Chem. Ref. Data Monograph 9, Parts I \& II, ACS \& AIP,Woodbury.

22. L. X. Benedict, S. G. Louie and M. L. Cohen, 1996, "Heat capacity of carbon nanotubes", Solid State Comm., 100, 177-180.

23. A. Borrell, A. Fernandez, C. Merino and R. Torrecillas, 2010, "High density carbon materials obtained at relatively low temperature by spark plasma sintering of carbon nanofibers”, Int. J. Mater. Res., 101, 112-118.

24. H. L. Zhang, J. F. Li, K. F. Yao and L. D. Chen, 2005, "Spark plasma sintering and thermal conductivity of carbon nanotube bulk materials”, J. Appl. Phys., 97, 114310.

25. A. Loiseau, P. Launois, P. Petit, S. Roche and J. P. Salvetat, J.P, (2006). Understanding carbon nanotubes from basics to application editors. Berlin Heidelberg, Springer.

26. G. D Zhan and A. K. Mukherjee, 2004, "Carbon nanotube reinforced Alumina-based ceramics with novel mechanical, electrical, and thermal properties”, Int. J. Appl. Ceram. Technol., 1, 161-171.

27. G. D. Zhan, J. D. Kuntz, J. Wan and A. K, Mukherjee, 2003, "Single-Wall Carbon Nanotube as Attractive Toughening Agents in Alumina-based Composites”, Nat. Mater., 2, $38-42$. 


\section{Figure captions:}

Figure 1. Variation of thermal conductivity with temperature for $\mathrm{CNFs} / \mathrm{Al}_{2} \mathrm{O}_{3}$ and $\mathrm{CNFs} / \mathrm{ZrO}_{2}$ nanocomposite and monolithic materials sintered at $1500{ }^{\circ} \mathrm{C}$ by SPS.

Figure 2. TEM images of the carbon nanofibers (a) before and (b) after spark plasma sintering at $1500{ }^{\circ} \mathrm{C}$. The microstructures of the nanofibers were remarkably densified after SPS.

Figure 3. Cooling rate for $\mathrm{CNFs} / \mathrm{Al}_{2} \mathrm{O}_{3}$ and $\mathrm{CNFs} / \mathrm{ZrO}_{2}$ nanocomposites and monolithic materials sintered at $1500{ }^{\circ} \mathrm{C}$ by SPS. 
Table I. Density of $\mathrm{CNFs} / \mathrm{Al}_{2} \mathrm{O}_{3}$ and $\mathrm{CNFs} / \mathrm{ZrO}_{2}$ nanocomposites and monolithic materials sintered by SPS at $1500{ }^{\circ} \mathrm{C}$ and $80 \mathrm{MPa}$ for 1 min under a vacuum.

\begin{tabular}{|c|c|c|}
\hline Samples & Density $\left(\mathbf{g} / \mathbf{c m}^{\mathbf{3}}\right)$ & $\begin{array}{c}\text { Relative density } \\
(\% \text { T.D })\end{array}$ \\
\hline $\mathrm{CNFs}$ & 1.71 & 89.4 \\
\hline $\mathrm{Al}_{2} \mathrm{O}_{3}$ & 3.96 & 99.9 \\
\hline $\mathrm{ZrO}_{2}$ & 6.07 & 99.9 \\
\hline $\mathrm{CNFs}+20 \mathrm{vol} \% \mathrm{Al}_{2} \mathrm{O}_{3}$ & 2.61 & 91.8 \\
\hline $\mathrm{CNFs}+80 \mathrm{vol} \% \mathrm{Al}_{2} \mathrm{O}_{3}$ & 3.52 & 98.9 \\
\hline $\mathrm{CNFs}+20 \mathrm{vol} \% \mathrm{ZrO}_{2}$ & 2.73 & 92.3 \\
\hline $\mathrm{CNFs}+80 \mathrm{vol} \% \mathrm{ZrO}_{2}$ & 5.24 & 98.8 \\
\hline
\end{tabular}



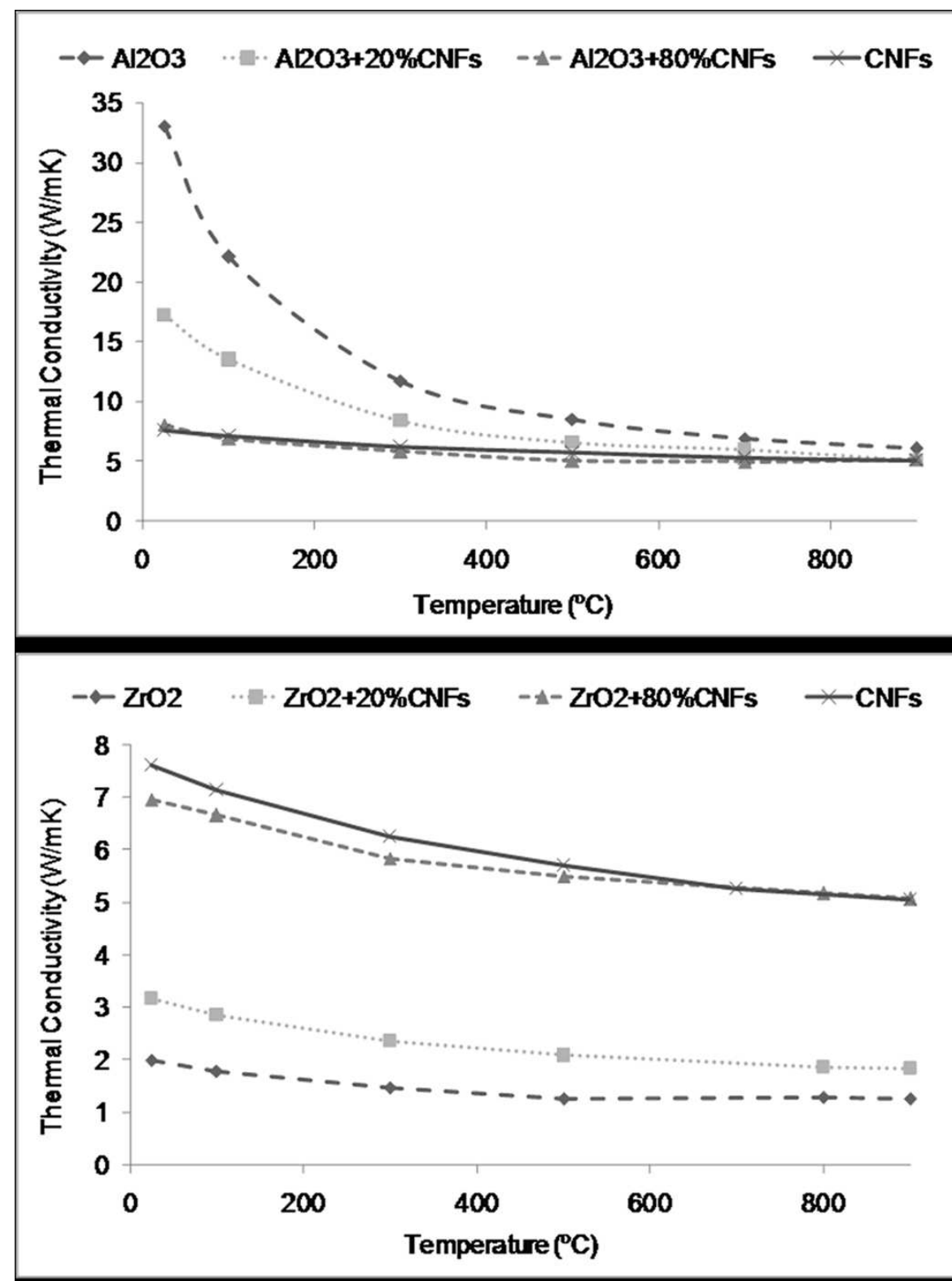
Variation of thermal conductivity with temperature for $\mathrm{CNFs} / \mathrm{Al} 2 \mathrm{O} 3$ and $\mathrm{CNFs} / \mathrm{ZrO} 2$ nanocomposite
and monolithic materials sintered at $1500^{\circ} \mathrm{C}$ by SPS. $76 \times 101 \mathrm{~mm}(350 \times 350 \mathrm{DPI})$ 


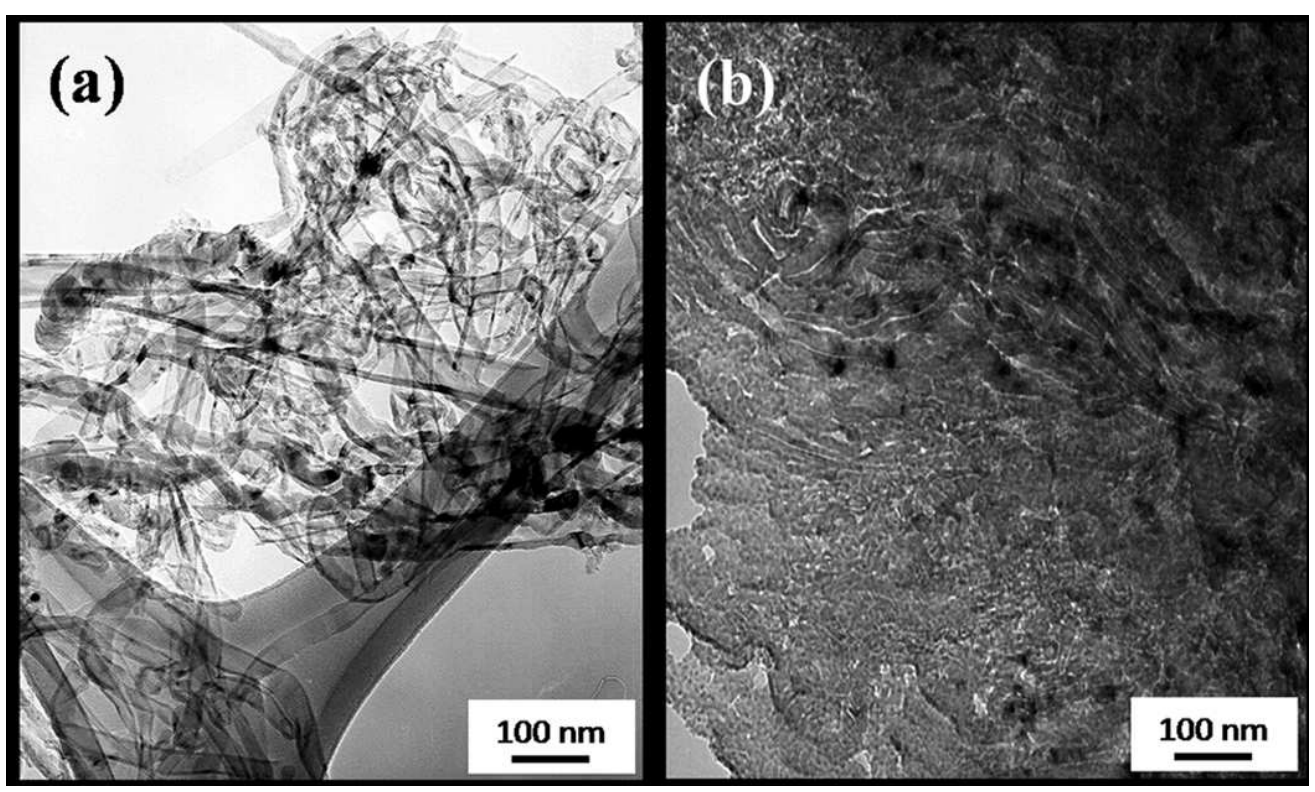

TEM images of the carbon nanofibers (a) before and (b) after spark plasma sintering at $15000^{\circ} \mathrm{C}$. The microstructures of the nanofibers were remarkably densified after SPS. $76 \times 45 \mathrm{~mm}(350 \times 350 \mathrm{DPI})$ 


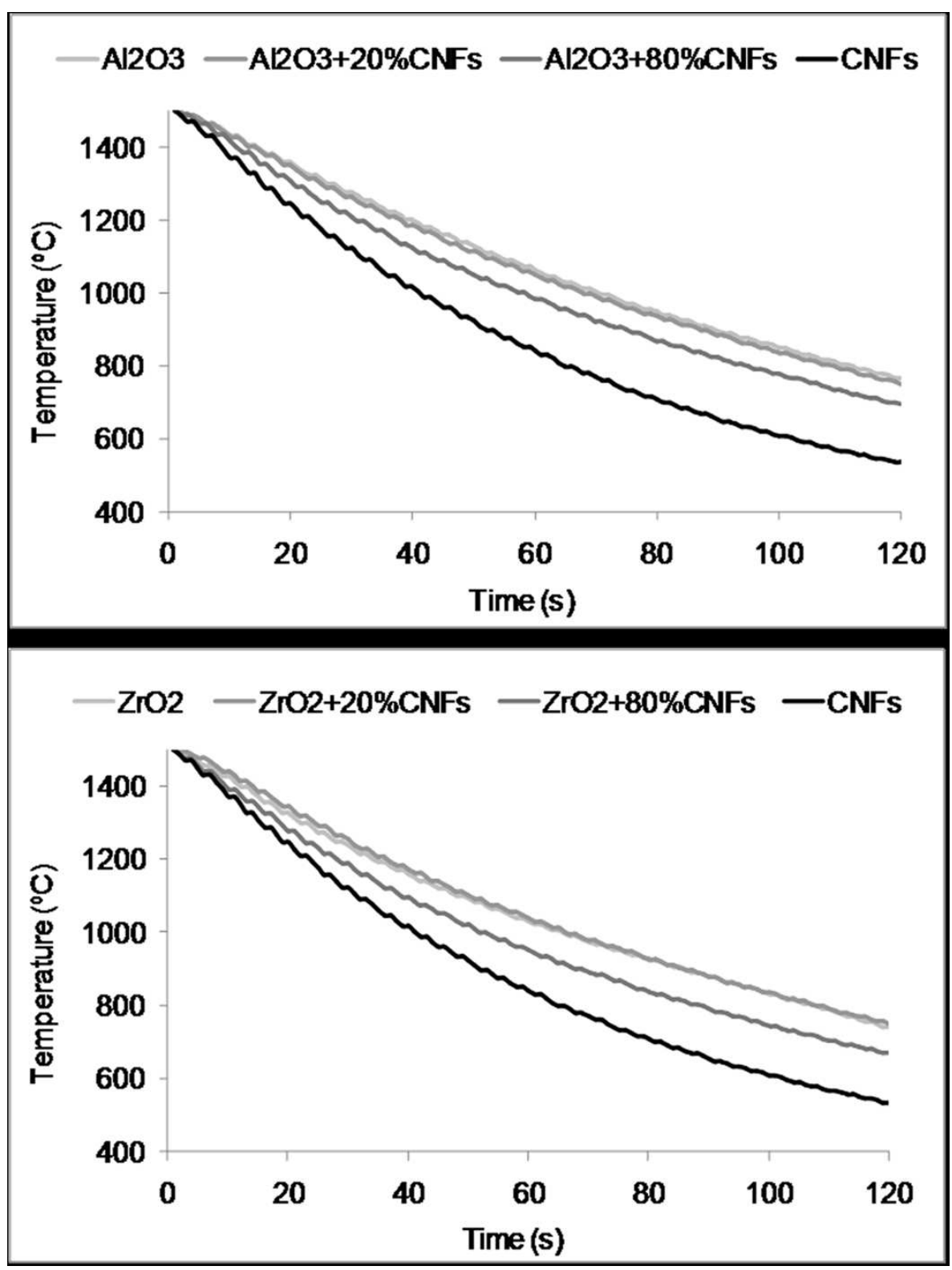

Cooling rate for CNFs/AI2O3 and CNFs/ZrO2 nanocomposites and monolithic materials sintered at $1500^{\circ} \mathrm{C}$ by SPS.

$76 \times 101 \mathrm{~mm}(350 \times 350 \mathrm{DPI})$ 